This item was submitted to Loughborough's Research Repository by the author.

Items in Figshare are protected by copyright, with all rights reserved, unless otherwise indicated.

\title{
Sleep quality and recommended levels of physical activity in older people
}

PLEASE CITE THE PUBLISHED VERSION

http://dx.doi.org/10.1123/japa.2014-0061

\section{PUBLISHER}

(c) Human Kinetics, Inc.

\section{VERSION}

AM (Accepted Manuscript)

\section{PUBLISHER STATEMENT}

This work is made available according to the conditions of the Creative Commons Attribution-NonCommercialNoDerivatives 4.0 International (CC BY-NC-ND 4.0) licence. Full details of this licence are available at: https://creativecommons.org/licenses/by-nc-nd/4.0/

\section{LICENCE}

CC BY-NC-ND 4.0

\section{REPOSITORY RECORD}

Hartescu, Iuliana, Kevin Morgan, and Clare Stevinson. 2019. "Sleep Quality and Recommended Levels of Physical Activity in Older People". figshare. https://hdl.handle.net/2134/19678. 
2 Minimum recommended levels of physical activity and sleep quality in older 3 people. 


\section{ABSTRACT}

2 The prevalence of insomnia symptoms increases with age, representing a major

3 challenge to public health. While high levels of activity and exercise training have

4 been associated with improvements in sleep quality across the lifespan, a minimum

5 level of activity likely to improve sleep outcomes among older people has not been

6 explored. This study investigated associations between walking at or above the

7 internationally recommended threshold of $\geq 150$ minutes per week and levels of

8 insomnia symptoms and sleep quality in later life. Within a nationally representative

9 UK sample aged 65+ $(n=926)$, cross-sectional regression models controlling for appropriate confounders showed that walking $\geq 150$ minutes per week was significantly associated with a lower likelihood of reporting insomnia symptoms (OR $=0.67(95 \% \mathrm{Cl}=0.45-0.91) \mathrm{p}<0.05)$, or reporting a lower sleep period percentage (of time in bed) $(\mathrm{OR}=0.70(95 \% \mathrm{Cl}=0.52-0.94 \mathrm{p}<0.05)$ at baseline. At 4 years follow-up ( $n=577)$, higher level at walking at baseline significantly predicted lower likelihood of problems getting to sleep $(\mathrm{OR}=0.64(95 \% \mathrm{Cl}=0.42-0.97 \mathrm{p}<0.05)$, and staying asleep $(\mathrm{OR}=0.63(95 \% \mathrm{Cl}=0.41-0.95 \mathrm{p}<0.05)$, but higher levels of walking did not significantly predict insomnia symptoms or sleep period percentage (OR = $0.70, \mathrm{~N} / \mathrm{S} ;$ and $\mathrm{OR}=1.32, \mathrm{~N} / \mathrm{S})$.

The criterion validity of the activity measure was separately demonstrated in a controlled survival analysis, which showed a significantly decreased 27-year mortality hazard associated with the higher ( $\geq 150$ minutes per week) walking level $(\mathrm{HR}=0.78(95 \% \mathrm{Cl}=0.68-0.84) \mathrm{p}<0.01)$. These results are consistent with the conclusion that physical activity guidelines are sufficient to sustain sleep quality in older adults. 


\section{INTRODUCTION}

2 Insomnia is most prevalent in later life (Sivertsen et al, 2009), independently

3 increasing health risk (Baglioni et al, 2011), service utilisation (see Rosekind and

4 Gregory, 2010), and economic burden (Daley et al, 2009; Rosekind and Gregory, 2010), and representing an international challenge to public health (Institute of Medicine, 2006; Stranges et al, 2014). While regular physical activity shows well established benefits in both the management of existing chronic disease (Leon et al, 2005; Colberg et al, 2010; Wipfli, Rethorst, \& Landers, 2008), and the prevention of future ill health (Sattelmair et al, 2011; Jeon, Lokken, Hu, \& Van Dam, 2007; Wolin, Yan, Colditz, \& Lee, 2009), growing evidence suggests that the benefits of physical activity can also extend to sleep. Epidemiological studies, for example, have shown that lower levels of physical activity represent a significant risk for prevalent and incident insomnia symptoms (Janson et al, 2001; Morgan, 2003), and both laboratory studies and randomized controlled trials have shown that increased levels of physical activity are associated with improvements in sleep quality and structure (King et al, 1997; King et al, 2008; Driver \& Taylor, 2000; Reid et al, 2010). However, from a public health perspective, two important limitations can be identified in the present sleep-exercise literature. First, much of the experimental attention in older people has focussed on relatively high intensity activities (see Montgomery \& Dennis, 2009; Yang, Ho, Chen, \& Chien, 2012). Whether lower, more widely achievable, levels of activity may be sufficient to deliver sleep benefits to older people remains under-researched, with only relatively recent evidence on different doses of exercise on sleep quality (Kline et al, 2012). And second, where survey assessments of physical activity have been associated with sleep quality (Buman et al, 2013), such assessments are rarely accompanied by evidence of 
1 health-related criterion validity for the activity measure (i.e. evidence that the

2 assessed level of activity is significantly associated with health outcomes). The present analyses were designed to address both of these issues.

$4 \quad$ In developing public health guidelines, systematic reviews have consistently found

5 that moderate intensity physical activity levels at or above a threshold value of 150

6 minutes per week reliably deliver health benefits, mitigating risk factors for, and the

7 impact of chronic diseases (Warburton et al, 2010). Although this overall weekly

8 volume of engagement appears beneficial irrespective of the type of activity

9 performed (Warburton et al, 2010), walking has been identified as the most convenient and achievable form of exercise for a high proportion of the adult population (Office of National Statistics, 2001). It remains unknown, however, whether a minimum of 150 minutes per week of walking is associated with improved sleep quality among older adults.

Using data from a longitudinal study of activity and health the principal aim of the present analyses was to assess cross-sectional and longitudinal relationships between currently recommended minimum activity levels and indices of subjective sleep qualityln order to evaluate the longer-term health relevance of the activity measure used, a secondary aim was to assess all-cause mortality within the activity groupings (i.e. those walking either above or below the threshold of 150 minutes/week) across the 27 year period 1985-2012. We hypothesise that, in comparisons of 2 survey groupings classified on the basis of reported walking activity, membership of the group walking at or above the recommended threshold (150 minutes/week) will be associated with significantly better sleep-related outcomes, and a significantly higher odds of 27 year survival. 
1

2

3

4

5

6

7

\section{METHODS}

Data were derived from the Nottingham Longitudinal Study of Activity and Ageing (NLSAA), full details of which are presented elsewhere (Morgan, 1998). Briefly, the NLSAA is an ongoing study of health outcomes among people originally aged 65 and over living in the UK. The baseline survey for the NLSAA was conducted between May and September 1985, during which time 1042 people, randomly sampled from general practitioners' lists, were interviewed in their own homes. Subsequent analyses showed that the age, sex, and social class structure of the sample closely resembled that for England and Wales as a whole at the time of sampling (Morgan, 1998). A full follow-up survey was conducted in 1989, with an overall re-interview rate of $88 \%$ ( $n=690$ ) obtained among survivors. Information on mortality (date, time, location, and recorded cause of death) within the baseline sample was provided by the UK Medical Research Information Service, allowing for ongoing survival analyses. Assessments relevant to the present analyses are briefly described below.

\section{Walking}

Levels of customary physical activity likely to promote muscle strength, joint flexibility, or stamina were assessed using detailed activity inventories administered in the single face-to-face interview (for a full descriptive overview of the activity data at each survey wave, see Armstrong and Morgan, 1998). In the assessment of walking, the interviewer asked in detail about walking done on a typical day, selecting preferentially the day prior to interview. If, however, this day had been atypical, then another was selected (up to a maximum of six days previously). For the purposes of the interview, the selected day was divided into hours, and the amount of walking (purposeful walking, shopping, and recreational walking) in each hour was coded in 
1 minutes, and finally expressed as minutes per typical day. These were then

2 aggregated in minutes per week.

\section{$3 \quad$ Sleep}

4 Subjectively estimated sleep quantity was assessed using the items: 1) "At what

5 time do you usually go to bed?"; 2) "At what time do you usually settle down in

6 bed to go to sleep?"; 3) How long does it normally take you to fall asleep?"; 4) "At

7 what time do you finally wake up?"; and 5) "At what time do you usually get up?".

8 Responses were then used to estimate time in bed (TIB: time elapsed between

9 going to bed and getting up); sleep latency (SL: time taken to fall asleep); and sleep period time (SPT: time from sleep onset to final awakening). An estimate of "sleep period percentage" (SP\%: the percentage of TIB occupied by the sleep period) was then calculated as: SP\% $=($ SPT/TIB $) \times 100)$. Since the present study did not estimate intervening wakefulness during the sleep period, a formal calculation of "total sleep time" (TST) was not possible. However, since subjective SPT provides a significant analogue of TST (Van Der Kloet, 2013), it is logical to assume that a lower SPE is indicative of less efficient sleep (where a lower proportion of TIB is actually spent sleeping). Insomnia symptoms were assessed using the item "Do you ever have problems sleeping (i.e. problems getting to sleep and/or staying asleep and/or waking too early?)", with five response categories (never, seldom, sometimes, often, all the time). Positive responses were followed with the question "Have you had this problem (or these problems) in the past week?" Insomnia symptoms were considered present if the respondent reported one or more sleep problem "often" or "all the time", and if that problem had been experienced within the previous week. (While separately reflecting subjective quantitative and qualitative estimates, SP\% and insomnia 
1 symptoms are not unrelated, since high proportions (>15\%) of TIB spent awake

2 typically indicate poor quality sleep, seePerlis, McCall, Jungquist, Pigeon, \&

3 Matteson, 2005).

4

$5 \quad$ Weight and Skeletal Size

6 At interview weight measurements (fully clothed with shoes removed) were made

7 using calibrated analogue scales. To reduce error arising from kyphotic changes in

8 measuring the height of older people, skeletal size was assessed using demispan

9 (Bassey, 1986), the distance between the finger roots and the sternal notch (with the arm laterally outstretched). Body mass was then estimated using the Quetelet Index

11 (BMI) based on weight and predicted height (Lehmann, Bassey, Morgan, \& Dallosso, 12 1991). Those with a $\mathrm{BMI}>25$ were judged to be overweight.

\section{Physical Health Status}

14 General health was assessed using a health index scored from zero (no health problems) to 13 (multiple health problems) covering the presence or absence of: heart, stomach, eyesight, or foot problems; giddiness, headaches, urinary

17 incontinence, arthritis, falls, and chronic disease; drug and walking aid use, and recent (1 month) contact with (primary and secondary care) medical services. The scale showed full activity across its score range (0-13) and acceptable reliability (Cronbach's alpha $=0.7$ ).

$\underline{\text { Mental Health Status }}$

Affective status was assessed using the separate anxiety and depression subscales from the Symptoms of Anxiety and Depression (SAD) Scale (Bedford, Foulds, \& Sheffield, 1976) which focuses exclusively on recent symptoms. 
1 Clinically significant levels of either anxiety or depression are indicated by

2 subscale scores of $\geq 4$. In validation trials conducted at baseline, scores at or

6 Cognitive Function

7 At the beginning of the interview all respondents were initially screened for

17 Statistical analyses cognitive impairment using the 12 -item Information/Orientation (I/O) scale from the Clifton Assessment Procedures for the Elderly (Pattie \& Gilleard, 1979). If, after appropriate prompting, the respondent failed to achieve a maximum I/O score of 8 and, in the opinion of the interviewer, was unlikely to respond reliably to the remaining questionnaire items, the interview was discontinued. In validation trials conducted at baseline, scores at or above this cutpoint showed high levels of concordance with clinical diagnostic ratings of dementia (kappa coefficient $=0.83, p<0.001 ;$ see Morgan, 1998).

\section{Statistical analyses}

Cross-sectional relationships between walking category (above/below the 150 minutes threshold) and subjective sleep variables at baseline were assessed in logistic regression models fitted separately for each sleep problem (present/absent), insomnia symptoms (present/absent) andsleep period percentage $(<85 \% / \geqslant 85 \%)$. Longitudinal relationships between walking category (at baseline) and the presence/absence of sleep problems, sleep period percentage, and individual insomnia symptoms reported at 4-year follow up were also assessed in logistic regression models. All models were adjusted for 
1 baseline: age $(65-70 ; 70-74 ; 75-7 ; 80+)$; sex; physical health status (above and

2 below median Health Index value); clinically significant levels of anxiety (yes/no)

3

4

5 To assess the longer-term health relevance of the walking measure used, the

6 relationship between walking category membership at baseline, and survival was assessed in a Cox regression model with survival (from baseline assessment in 1985 to death or censorship in March 2012) as dependent, and baseline: age (65-70; 70-74; 75-7; 80+); sex; physical health status (above and below median Health Index value);clinically significant levels of anxiety (yes/no) and depression (yes/no); BMI ( $\leq 25 ;>25)$ and social class (managerial/professional; skilled/semiskilled; unskilled) as covariates. A forced entry approach to model selection was used. Initial examination of the log-minus-log plot of the survival functions showed no departure from the assumption of proportional hazards.

All data were analysed using SPSS for Windows v 20.0.

\section{RESULTS}

From the original baseline sample of 1042 , information on both physical activity and subjective sleep quantity and quality was available from 926 respondents (with omissions due primarily to cognitive impairment or physical disability at baseline). At 4-year follow-up, information on subjective sleep variables was available from 577 survivors. Sample characteristics are shown in Table1. Overall, $49 \%$ of the sample reported sleep period percentages below $85 \%$. The average sleep duration within the sample was $7 \mathrm{~h} 8 \mathrm{~min}$, with a median duration of $7 \mathrm{~h} 15 \mathrm{~min}$. Frequent (i.e. 'often/all 
1 the time') problems getting to sleep, or staying asleep were the most frequently

2 reported sleep difficulties (reported by $28 \%$ and $25 \%$ of respondents respectively),

3 with early morning waking reported by $13 \%$. Overall, $21.6 \%$ of the baseline sample

4 met survey criteria for insomnia symptoms with women showing a significantly

5 greater prevalence than men (Figure 1). The activity threshold of $\geq 150$ walking

6 minutes/week divided the sample at baseline into $37 \%$ above, and $63 \%$ below the

7 recommended guidelines. The median weekly walking duration at baseline was 45

8 minutes/week.

Results from the logistic regression models examining relationships between walking levels and baseline sleep variables are shown in Table 2. The higher level of walking was significantly and independently associated with a lower likelihood of either reporting insomnia symptoms $(\mathrm{OR}=0.67(95 \% \mathrm{Cl}=0.45-0.91) \mathrm{p}<0.05)$, or a lower sleep period percentage $(\mathrm{OR}=0.70(95 \% \mathrm{Cl}=0.52-0.94 \mathrm{p}<0.05)$. In the logistic regression analyses of 4-year follow-up data, higher levels of walking (at baseline) did not significantly predict insomnia symptoms or sleep period percentage (OR = 0.70, and $\mathrm{OR}=1.32$, all non-significant respectively). We performed exploratory analyses on the individual insomnia symptoms, and we found that the higher level at walking at baseline significantly predicted a lower likelihood of problems getting to sleep $(\mathrm{OR}=0.64(95 \% \mathrm{Cl}=0.42-0.97) \mathrm{p}<0.05)$, and staying asleep $(\mathrm{OR}=0.63(95 \%$ $\mathrm{Cl}=0.41-0.95) \mathrm{p}<0.05)$, but not early morning awakening $(\mathrm{OR}=0.63, \mathrm{~ns})$ four years later (Table 3). In the 27-year period 1985-2012 the project received notification of 878 deaths within the sample of 926 participants included in this study. Results from Cox regression 
1 analyses are shown in Table 4. The survival model showed that, after controlling for

2 age, sex, and baseline measures of physical health, anxiety, depression, and social

\section{DISCUSSION}

7 Given the representativeness of the original NLSAA survey sample, and the

8 relatively high response rates obtained at baseline, the present analyses offer a robust test of associations between moderate physical activity, at or above the recommended threshold value of 150 minutes/week, and insomnia symptoms prevalence, independent of concomitant health status at baseline. Several factors support the validity of the insomnia measure used in these analyses: the sleep problems audited in this survey reflect the cardinal symptoms of insomnia used in current nosologies (e.g. DSM V; American Psychiatric Association, 2013); analyses of baseline data (Morgan et al, 1988) showed a high degree of convergent validity among these sleep measures, with insomnia symptoms predicting shorter subjective sleep periods, longer subjective sleep latencies and lower sleep period percentages. Estimates of insomnia prevalence (Morgan et al, 1988) and incidence (Morgan and Clarke,1997) using these measures fit comfortably within the range of internationally reported values from representative samples (see Morgan, 2012); and the classification of "insomnia symptoms" used in the present analyses accords with the criteria proposed by Ohayon (2002). Furthermore, that the survival analyses found a significantly lower mortality risk in those walking above the recommended threshold (independent of confounding health and demographic variables) offers support for the criterion of the walking measure used here, , where walking over 150 minutes 
1 (2.5 hours) a week was associated with increased survival at 27-year follow up,

2 amounting to a $22 \%(0.78)$ decrease in hazard rate. The reduction in our analysis is

7 consistent with that reported in other studies examining survival risks associated with physical activity generally (e.g., Hamer \& Chida, 2009) or walking specifically (Samitz et al, 2011: 0.93 (0.87-0.97); Woodcock, Franco, Orsini, \& Roberts, 2011: $0.89(0.82-0.96))$

The overall pattern of the present findings indicates that even a relatively low intensity activity, such as walking to the level of the current guidelines, achievable by most older people, is associated with a significantly reduced likelihood of reporting sleep problems and insomnia symptoms, and significantly greater sleep period percentage. It would appear, then, that in general, older people who walked more, slept better. While the control variables used in the cross sectional analyses suggest that this association between higher activity and superior sleep quality is independent of mental and physical health factors, the possibility of inadequate statistical control, and reverse causality (where poorer sleep quality influences the capacity or motivation to walk) cannot be excluded. There are proposed reciprocal dynamic effects models between physical activity and sleep (Dzierzewski et al, 2014; Chennaoui et al, 2014), emphasising the potential to modify either of these behaviours to affect the other. However, the ability of baseline walking levels to predict the presence of sleep problems at the 4-year follow-up offers additional support for a conclusion that the present findings are consistent with a walking facilitated sleep benefit. Indicative of a dose-response relationship, the present results also show a more modest odds reduction than that shown when higher levels 
1 of habitual physical activity are examined in relation to sleep outcomes (e.g. Hublin,

2 Kaprio, Partinen, \& Koskenvuo, 2001; Kim et al, 2009).

4 Though longitudinally predictive of individual sleep problems, levels of walking were

5 not significantly related to insomnia symptoms at follow-up, suggesting a weakening

6 of the relationship over time. It is relevant to note, however, that increasing morbidity

7 and mortality within the sample, ontogenetic change in sleep variables, and

8 changing social dynamics relevant to sleep (for example bereavement and the

9 transition to sleeping alone), could all contribute to a shift in activity-sleep

10 relationships. An adequate exploration of these and other factors is beyond the

11 scope of the present paper, but now presents an important area for future research.

While there are established physiological mechanisms to account for the association between physical activity and survival (Taylor et al, 2004), there is less consensus on factors which may be mediating the effects of physical activity on sleep quantity and quality. Youngstedt (2005) has proposed that physical activity may alleviate sleeping difficulties through anxiety reduction, since anxiety is an independent risk factor for the onset of insomnia symptoms (Johnson, Roth, \& Breslau, 2006). This view is supported both by evidence suggesting that acute and chronic exercise can lead to stable reductions in the manifestations of trait anxiety (O'Connor, Raglin, \& Martinsen, 2000; Herring, O'Connor, \& Dishman, 2010) and by the significance added to our own models by anxiety symptoms. A further possibility is that regular outdoor activity, independent of its intensity, increases exposure to light and, as a result, better maintains circadian entrainment (Gordjin, Beersma, Korte, \& Van den Hoofdakker 1998; Youngstedt et al, 2003). This latter mechanism may be 
1 particularly relevant to older people among whom levels of melatonin, the hormone

2 which mediates the circadian rhythm's entrainment to light, are known to decrease

3 (Leger, Laudon \& Zisapel, 2004). In an observational study of sleep quality and exercise Youngstedt et al (2003), found that the mean reported time spent outdoors was almost three times higher on days when participants were active, than on days when they were not active.

Only a small percentage of older people are functionally impaired to the extent of not being able to walk independently (Age UK, 2013). We acknowledge, however, the evident limitations of secondary analyses performed on data collected from an earlier generation of older people. Changes in physical activity and general health trends over the past 27 years, coupled with an increase in overweight/obesity trends could have introduced generational or cohort effects which impacted the key variables reported here. However, while these trends may have influenced the overall levels of walking in the contemporary older population aged $65+$, it is less clear how secular change would impact relationships between walking and health and wellbeing outcomes. A further limitation of the present analyses concerns the assessment of sleep itself, which did not include a measure of intervening wakefulness (i.e. wakefulness during the sleep period). While this omission prevented the accurate estimation of sleep efficiency (where sleep efficiency = (SPT-wakefulness during sleep)/TIB $\times 100$ ), the pattern of results reported here is consistent with the view that the SP\% variable did provide a reasonable proxy for sleep efficiency. That the relationships identified in our study accord with contemporary findings, and can be accounted for by plausible biological mechanisms, also supports the validity of the conclusions drawn and, at the very least, offers 'proof of concept' that physical 
1 activity-sleep relationships operate on a continuum even at relatively low intensity

2 levels of activity. 
1 FIGURES AND TABLES

2

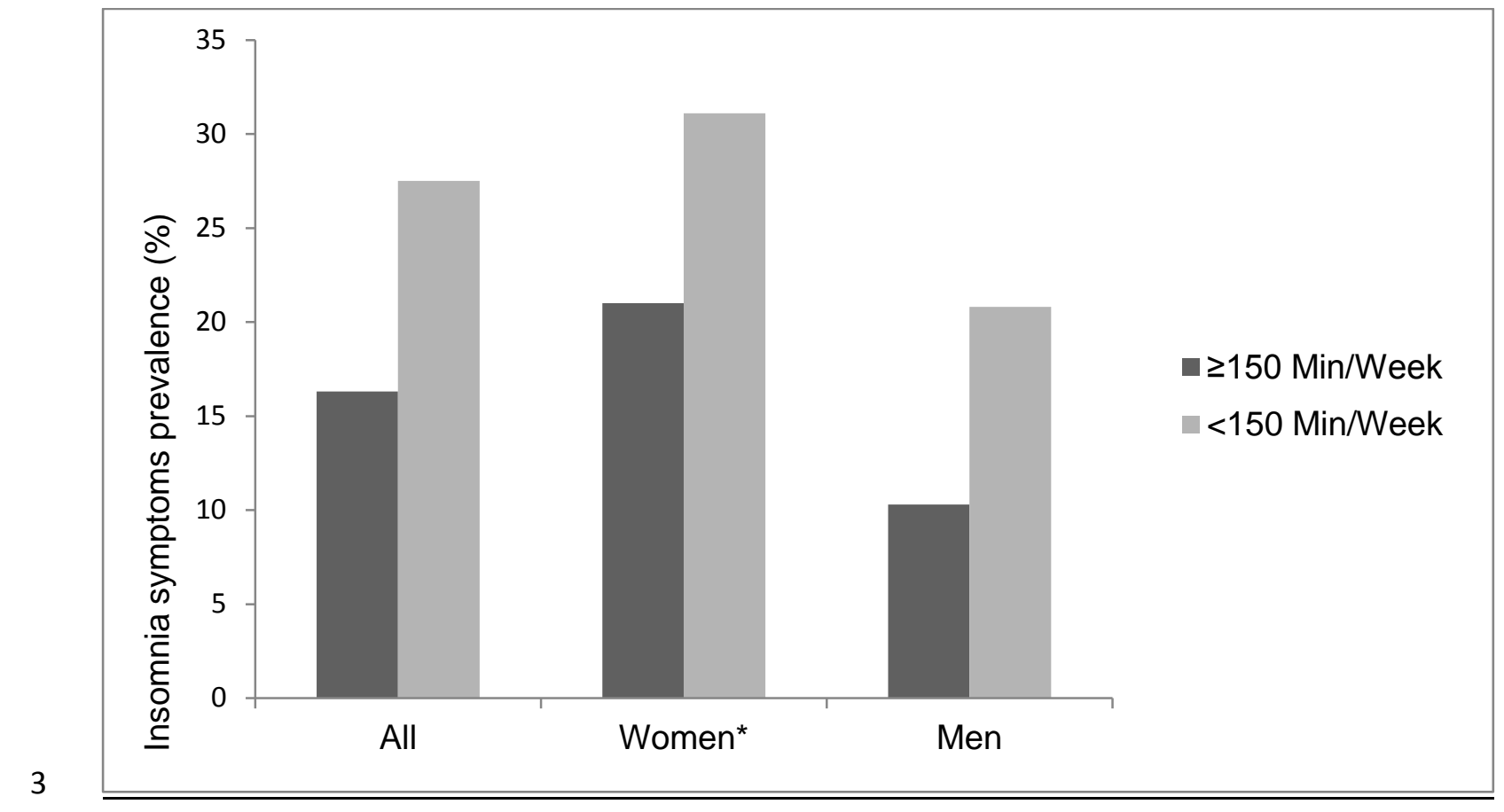

4 Figure 1. Prevalence of insomnia symptoms in each walking category at baseline (1985).

$5 \quad$ *Significant association between insomnia symptoms prevalence and gender: $X^{2}(1)=19.29, p, 0.001$. 6 
1 Table 1

2 Sample characteristics at baseline

\begin{tabular}{llll}
\hline Baseline & $<150 \mathrm{~min} /$ week of PA & $\geq 150 \mathrm{~min} /$ week of PA \\
\hline & Total N: 926 & 580 & 346 \\
\hline Men & $n / \%$ & $n / \%$ \\
Women & $221(38)$ & $148(43)$ \\
Sleep period percentage & $273(47)$ & $197(57)$ \\
below 85\% & & $175(51)$ \\
Insomnia symptoms* & $146(25)$ & $56(16)$ \\
Trouble falling asleep & $167(29)$ & $92(27)$ \\
Trouble maintaining sleep & $163(28)$ & $68(20)$ \\
Early morning awakening & $74(13)$ & $48(13)$
\end{tabular}

4-year

follow up

\begin{tabular}{lll}
\hline Total N: $\mathbf{5 7 7}$ & $\mathbf{3 7 6}$ & $\mathbf{2 0 1}$ \\
\hline Men & $n / \%$ & $n / \%$ \\
Women & $131(35)$ & $104(52)$ \\
Sleep period percentage & $180(48)$ & $157(48)$ \\
below 85\% & $221(65)$ & $98(49)$ \\
Insomnia symptoms* & $98(26)$ & $5427)$ \\
Trouble falling asleep & $106(28)$ & $57(28)$ \\
Trouble maintaining sleep & $101(27)$ & $54(27)$ \\
Early morning awakening & $71(19)$ & $36(18)$
\end{tabular}

* Any of the three insomnia symptoms, reported frequency of 'often' or 'all the time', and experienced within

4 the last week. 
1 Table 2

2 Odds ratios and 95\% confidence intervals for sleep variables in walking categories

\begin{tabular}{lcccc} 
Models baseline* & $\mathrm{B}(\mathrm{SE})$ & Odds Ratio & $95 \% \mathrm{Cl}$ & $\mathrm{p}^{*}$ \\
\hline Insomnia symptoms** & & & & \\
Walking category (lower) & $-0.40(0.20)$ & 0.67 & $0.45-0.91$ & $<0.05$
\end{tabular}

Subjective sleep period

percentage

$\begin{array}{lllll}\text { Walking category (lower) } & -0.35(0.15) & 0.70 & 0.52-0.94 & <0.05\end{array}$

\footnotetext{
*All models included covariates: physical health status, age, sex, depression, anxiety, social class and body mass index.

**Defined as the presence any of the three insomnia symptoms, reported frequency of often or all the time, and experienced within the last week.
} 
1 Table 3

2 Odds ratios and confidence intervals for the sleep variables in walking categories at 4-year

3 follow up

\begin{tabular}{lcccc}
\multicolumn{1}{c}{ Models 4-year follow up* } & $\mathrm{B}(\mathrm{SE})$ & Odds Ratio & $95 \% \mathrm{Cl}$ & $\mathrm{p}^{*}$ \\
\hline Insomnia symptoms** & & & & \\
Walking category (lower) & $-0.35(0.21)$ & 0.70 & $0.46-1.07$ & $=0.10$
\end{tabular}

Subjective sleep period

percentage

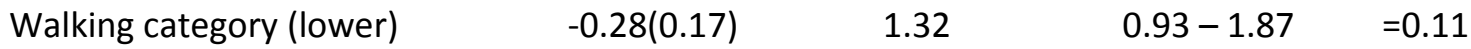

Separate insomnia symptoms presence

$\begin{array}{lllll}\text { Problems getting to sleep } & -0.43(0.21) & 0.64 & 0.42-0.97 \quad<0.05\end{array}$

$\begin{array}{lllll}\text { Problems staying asleep } & -0.45(0.21) & 0.63 & 0.41-0.97 \quad<0.05\end{array}$

$\begin{array}{lllll}\text { Early morning awakening } & -0.44(0.25) & 0.63 & 0.39-1.04 \quad=0.07\end{array}$

4 *All models included covariates: physical health status, age, sex, depression, anxiety, social class and body 5 mass index.

$6 * *$ Defined as the presence any of the three insomnia symptoms, reported frequency of often or all the time, 7 and experienced within the last week. 
1 Table 4

2 Hazard ratios and 95\% confidence intervals for 27-year mortality ( $n=926 ; 5 \%$ survival rate)

\begin{tabular}{|c|c|c|c|}
\hline Model \& Variables & Hazard Ratio & $95 \% \mathrm{Cl}$ & $p^{*}$ \\
\hline Walking category (lower) & 0.78 & $0.68-0.90$ & $<0.01$ \\
\hline $\operatorname{Age}^{\mathrm{b}}$ & 1.41 & $1.15-1.73$ & $<0.001$ \\
\hline Sex (male) & 0.70 & $0.62-0.81$ & $<0.001$ \\
\hline $\begin{array}{l}\text { Physical Health Status } \\
\text { (higher category) }\end{array}$ & 1.30 & $1.11-1.51$ & $<0.001$ \\
\hline BMI & 0.86 & $0.74-0.99$ & $<0.05$ \\
\hline Anxiety & 1.12 & $0.90-1.41$ & $=0.29$ \\
\hline Depression & 0.92 & $0.71-1.21$ & $=0.58$ \\
\hline Social Class (Class I \& II) & 1.04 & $0.86-1.27$ & $=0.63$ \\
\hline
\end{tabular}

5

6 
1

\section{REFERENCES}

Age UK (2013). Later life in the United Kingdom. Retried April, 23, 2013 from http://www.ageuk.org.uk/Documents/ENGB/Factsheets/Later_Life_UK_factsheet.pdf?dtrk=true.

Armstrong, G. K., \& Morgan, K. (1998). Stability and change in levels of habitual physical activity in later life. Age and Ageing, 27(suppl 3), 17-23.

Baglioni, C., Battagliese, G., Feige, B., Spiegelhalder, K., Nissen, C., Voderholzer, U., et al. (2011). Insomnia as a predictor of depression: A meta-analytic evaluation of longitudinal epidemiological studies. Journal of Affective Disorders, 135(1), 10-19.

Bassey, E. J. (1986). Demi-span as a measure of skeletal size. Annals of Human Biology, 13(5), 499-502.

Bedford, A., Foulds, G., \& Sheffield, B. (1976). A new personal disturbance scale (DSSI/SAD). British Journal of Social and Clinical Psychology, 15(4), 387-394.

Brownson, R. C., Boehmer, T. K., \& Luke, D. A. (2005). Declining rates of physical activity in the United States: What are the contributors? Annual Review of Public Health, 26, 421-443.

Buman, M. P., Phillips, B. A., Youngstedt, S. D., Kline, C. E., \& Hirshkowitz, M. (2014). Does nighttime exercise really disturb sleep? Results from the 2013 National Sleep Foundation Sleep in America Poll. Sleep Medicine, 15(7), 755761. 
1 Chennaoui, M., Arnal, P. J., Sauvet, F., \& Léger, D. Sleep and exercise: A reciprocal issue? Sleep Medicine Reviews, in press.

Colberg, S. R., Sigal, R. J., Fernhall, B., Regensteiner, J. G., Blissmer, B. J., Rubin, R. R., . . Braun, B. (2010). Exercise and Type 2 Diabetes: The American College of Sports Medicine and the American Diabetes Association: Joint position statement. Diabetes Care, 33(12), e147-e167.

Craig, R., Mindell, J., \& Hirani, V. (Eds). (2009). Health Survey for England 2008: Physical activity and fitness. NHS Information Centre: Leeds. Accessed April, 4, 2013 from http://www.hscic.gov.uk/pubs/hse08physicalactivity.

[DSM v] American Psychiatric Association. (2013). Diagnostic and statistical manual of mental disorders (5th ed.). Arlington, VA: American Psychiatric Publishing.

Daley, M., Morin, C. M., LeBlanc, M., Gregoire, J. P., \& Savard, J. (2009). The economic burden of insomnia: Direct and indirect costs for individuals with insomnia syndrome, insomnia symptoms, and good sleepers. Sleep, 32(1), 5564.

Dzierzewski, J. M., Buman, M. P., Giacobbi, P. R., Roberts, B. L., Aiken-Morgan, A. T., Marsiske, M., et al. (2014). Exercise and sleep in community-dwelling older adults: Evidence for a reciprocal relationship. Journal of Sleep Research, 23(1), 61-68.

Department for Transport. (2012). Local area walking and cycling: England 2010/2011. Retrieved September, 13, 2012 from http://www.dft.gov.uk/statistics/series/walking-and-cycling/. 
1 Donnelly, J., Blair, S., Jakicic, J., Manore, M., Rankin, J., \& Smith, B. (2009). American College of Sports Medicine position stand: Appropriate physical activity intervention strategies for weight loss and prevention of weight regain for adults. Medicine and Science in Sports and Exercise, 41(2), 459-471.

Driver, H. S., \& Taylor, S. R. (2000). Exercise and sleep. Sleep Medicine Reviews, $4(4), 387-402$.

Friedenreich, C. M. (2011). Physical activity and breast cancer: Review of the epidemiologic evidence and biologic mechanisms. Clinical Cancer Prevention (pp. 125-139) Springer.

Gordijn, M., Beersma, D. G. M., Korte, H. J., \& Van den Hoofdakker, R. H. (1998). Testing the hypothesis of a circadian phase disturbance underlying depressive mood in nonseasonal depression. Journal of Biological Rhythms, 13(2), 132-147.

Gordon, N. F., Gulanick, M., Costa, F., Fletcher, G., Franklin, B. A., Roth, E. J., \& Shephard, T. (2004). Physical activity and exercise recommendations for stroke survivors: An American Heart Association scientific statement from the Council on Clinical Cardiology, Subcommittee on Exercise, Cardiac rehabilitation, and Prevention; the Council on Cardiovascular Nursing; the Council on Nutrition, Physical activity, and Metabolism; and the Stroke Council. Circulation, 109(16), 2031-2041.

Hamer, M., \& Chida, Y. (2009). Physical activity and risk of neurodegenerative disease: A systematic review of prospective evidence. Psychological Medicine, 39(1), 3. 
1 Herring, M. P., O'Connor, P. J., \& Dishman, R. K. (2010). The effect of exercise training on anxiety symptoms among patients: A systematic review. Archives of Internal Medicine, 170(4), 321-331.

4

Hublin, C., Kaprio, J., Partinen, M., \& Koskenvuo, M. (2001). Insufficient sleep - A population-based study in adults. Sleep, 24(4), 392-400.

[Institute of medicine] Altevogt, B. M., \& Colten, H. R. (2006). Sleep disorders and sleep deprivation: An unmet public health problem. National Academies Press.

Jeon, C. Y., Lokken, R. P., Hu, F. B., \& Van Dam, R. M. (2007). Physical activity of moderate intensity and risk of type 2 diabetes: A systematic review. Diabetes Care, 30(3), 744-752.

Johnson, E. O., Roth, T., \& Breslau, N. (2006). The association of insomnia with anxiety disorders and depression: Exploration of the direction of risk. Journal of Psychiatric Research, 40(8), 700-708.

Kim, J., Stewart, R., Kim, S., Yang, S., Shin, I., \& Yoon, J. (2009). Insomnia, depression, and physical disorders in late life: A 2-year longitudinal community study in Koreans. Sleep: Journal of Sleep and Sleep Disorders Research, 32(9), 1221-1228.

Lee, I., Shiroma, E. J., Lobelo, F., Puska, P., Blair, S. N., \& Katzmarzyk, P. T. (2012). Effect of physical inactivity on major non-communicable diseases worldwide: An analysis of burden of disease and life expectancy. The Lancet, 380(9383, 219229. 
1 Leger, D., Laudon, M., \& Zisapel, N. (2004). Nocturnal 6-sulfatoxymelatonin excretion in insomnia and its relation to the response to melatonin replacement therapy. American Journal of Medicine, 116(2), 91-95.

Lehmann, A., Bassey, E., Morgan, K., \& Dallosso, H. (1991). Normal values for weight, skeletal size and body mass indices in 890 men and women aged over 65 years. Clinical Nutrition, 10(1), 18-22.

Leon, A. S., Franklin, B. A., Costa, F., Balady, G. J., Berra, K. A., Stewart, K. J., . . . Lauer, M. S. (2005). Cardiac rehabilitation and secondary prevention of coronary heart disease: An American Heart Association scientific statement from the Council on Clinical Cardiology (Subcommittee on Exercise, Cardiac rehabilitation, and Prevention) and the Council on Nutrition, Physical Activity, and Metabolism (Subcommittee on Physical Activity), in collaboration with the American Association of Cardiovascular and Pulmonary Rehabilitation. Circulation, 111(3), 369-376.

Morgan, K. (1998). The nottingham longitudinal study of activity and ageing: A methodological overview. Age and Ageing, 27(suppl 3), 5-11.

Morgan, K. (2003). Daytime activity and risk factors for late-life insomnia. Journal of Sleep Research, 12(3), 231-238.

Morgan, K. (2012). The epidemiology of sleep. In Morin, C. M., \& Espie, C. A. (Eds.), The Oxford handbook of sleep and sleep disorders (pp. 303-323), New York, NY: OUP. 
1 Morgan, K., \& Clarke, D. (1997). Risk factors for late-life insomnia in a representative general practice sample. The British Journal of General Practice : The Journal of the Royal College of General Practitioners, 47(416), 166-169.

O'Connor, P., Raglin, J., \& Martinsen, E. (2000). Physical activity, anxiety and anxiety disorders. International Journal of Sport Psychology, 31(2), 136-155.

Office for National Statistics. (2001). Psychiatric morbidity among adults living in private households, 2000. London: The Stationery Office.

Ohayon, M. (1996). Epidemiological study on insomnia in the general population. Sleep, 19(3 SUPPL.), S7-S15.

Ohayon, M. M. (2002). Epidemiology of insomnia: What we know and what we still need to learn. Sleep Medicine Reviews, 6(2), 97-111.

Pattie, A., \& Gilleard, C. (1979). Manual for the Clifton assessment procedures for the Elderly (CAPE). Sevenoaks, Kent: Hodder \& Stoughton.

Perlis, M. L., McCall, W. V., Jungquist, C. R., Pigeon, W. R., \& Matteson, S. E. (2005). Placebo effects in primary insomnia. Sleep Medicine Reviews, 9(5), 381389.

Reid, K. J., Baron, K. G., Lu, B., Naylor, E., Wolfe, L., \& Zee, P. C. (2010). Aerobic exercise improves self-reported sleep and quality of life in older adults with insomnia. Sleep Medicine, 11(9), 934-940.

Rethorst, C. D., Wipfli, B. M., \& Landers, D. M. (2009). The antidepressive effects of exercise. Sports Medicine, 39(6), 491-511. 
1 Rosekind, M. R., \& Gregory, K. B. (2010). Insomnia risks and costs: Health, safety, and quality of life. Am J Manag Care, 16(8), 617-626.

Samitz, G., Egger, M., \& Zwahlen, M. (2011). Domains of physical activity and allcause mortality: Systematic review and dose-response meta-analysis of cohort studies. International Journal of Epidemiology, 40(5), 1382-1400.

Sattelmair, J., Pertman, J., Ding, E. L., Kohl III, H. W., Haskell, W., \& Lee, I. (2011). Dose response between physical activity and risk of Coronary Heart DiseaseClinical perspective: A meta-analysis. Circulation, 124(7), 789-795.

Sivertsen, B., Overland, S., Pallesen, S., Bjorvatn, B., Nordhus, I. H., Maeland, J. G., et al. (2009). Insomnia and long sleep duration are risk factors for later work disability. The Hordaland Health Study. [Article]. Journal of Sleep Research, 18(1), 122-128.

Stranges, S., Tigbe, W., Gomez-Olive, F. X., Thorogood, M., \& Kandala, N. B. (2012). Sleep problems: An emerging global epidemic? Findings from the INDEPTH WHO-SAGE study among more than 40,000 older adults from 8 countries across Africa and Asia. Sleep, 35(8), 1173-1181.

Taylor, A., Cable, N., Faulkner, G., Hillsdon, M., Narici, M., \& Van Der Bij, A. (2004). Physical activity and older adults: A review of health benefits and the effectiveness of interventions. Journal of Sports Sciences, 22(8), 703-725.

The NHS Information Centre. (2013). Statistics on obesity, physical activity and diet: England, 2012. Retrieved 23, April 2013, from: http://www.ic.nhs.uk/pubs/opad12. 
2 Van Der Kloet, D., Giesbrecht, T., Franck, E., Van Gastel, A., De Volder, I., Van Den Eede, F., et al. (2013). Dissociative symptoms and sleep parameters - an allnight polysomnography study in patients with insomnia. Comprehensive Psychiatry, 54(6), 658-664.

Warburton, D., Charlesworth, S., Ivey, A., Nettlefold, L., \& Bredin, S. (2010). A systematic review of the evidence for Canada's physical activity guidelines for adults. The International Journal of Behavioral Nutrition and Physical Activity, 7(1), 39.

Wipfli, B. M., Rethorst, C. D., \& Landers, D. M. (2008). The anxiolytic effects of exercise: A meta-analysis of randomized trials and dose-response analysis. Journal of Sport \& Exercise Psychology, 30(4), 392-410.

Wolin, K., Yan, Y., Colditz, G., \& Lee, I. (2009). Physical activity and colon cancer prevention: A meta-analysis. British Journal of Cancer, 100(4), 611-616.

Woodcock, J., Franco, O. H., Orsini, N., \& Roberts, I. (2011). Non-vigorous physical activity and all-cause mortality: Systematic review and meta-analysis of cohort studies. International Journal of Epidemiology, 40(1), 121-138.

Yang, P., Ho, K., Chen, H., \& Chien, M. (2012). Exercise training improves sleep quality in middle-aged and older adults with sleep problems: A systematic review. Journal of Physiotherapy, 58(3), 157-163.

Youngstedt, S. D. (2005). Effects of exercise on sleep. Clinics in Sports Medicine, 24(2), 355-365. doi:10.1016/j.csm.2004.12.003 
1 Youngstedt, S. D., Perlis, M. L., O'Brien, P. M., Palmer, C. R., Smith, M. T., Orff, H. J., \& Kripke, D. F. (2003). No association of sleep with total daily physical activity in normal sleepers. Physiology \& Behavior, 78(3), 395-401. doi:10.1016/S00319384(03)00004-0. 